\title{
Microsomal Liver Function in Patients with Phenylketonuria Assessed by 13C-Methacetin Breath Test
}

\author{
Renata Mozrzymas, ${ }^{1}$ Monika Dus-Zuchowska, ${ }^{2}$ Lukasz Kaluzny, ${ }^{2}$ Anna Miskiewicz-Chotnicka, \\ Aleksandra Lisowska, ${ }^{2}$ and Jaroslaw Walkowiak ${ }^{2,}{ }^{*}$ \\ ${ }^{1}$ Voivodeship Hospital, Wroclaw, Poland \\ ${ }^{2}$ Department of Pediatric Gastroenterology and Metabolic Diseases, Poznan University of Medical Sciences, Poznan, Poland \\ "Corresponding author: Jarosław Walkowiak, Department of Pediatric Gastroenterology and Metabolic Diseases, Poznan University of Medical Sciences, Ul. Szpitalna 27/33, 60 - \\ 572 Poznan, Poland. Tel: +48-618491432, E-mail: jarwalk@ump.edu.pl
}

Received 2017 May 04; Revised 2017 July 17; Accepted 2017 October 14.

\begin{abstract}
Background: Although the activity of the cytosolic hepatic enzyme phenylalanine hydroxylase is impaired in phenylketonuria (PKU), the microsomal function, necessary for the metabolism of xenobiotics, has never been assessed. The aim of the study was to assess the microsomal liver function in PKU patients by 13C-methacetin breath test (13C-MBT), which measures cytochrome P450 activity.

Methods: Twenty patients with classical PKU, aged 15 - 34 years, were enrolled in the study. The control group comprised of 20 healthy subjects matched for age and sex. The 13C-MBT was performed in every subject at rest after an overnight fast.

Results: The values of cumulative percentage dose recovery at 120 minutes of the test (CPDR median $<$ interquartile range $>$ ) were significantly lower in the PKU group than in the control group $(25.1<21.8-28.83>$ vs $32.8<27.4-34.1>$; $\mathrm{P}=0.0067)$. The lower values of the maximum momentary 13C recovery (Dmax) were observed in the PKU group than in the control group $(26.6<22.4$ - 28.7 $>$ vs. $32.1<27.18$ - 34.08 > $P=0.0227)$. The values of time to reach $D \max (\operatorname{Tmax}) \operatorname{did}$ not $\operatorname{differ}(20<17-20>$ vs. $20<20-20>$; $\mathrm{P}=0.8410)$. The values of CPDR, Dmax and Tmax were not different between the group with abnormal $(>10 \mathrm{mg} / \mathrm{dL})$ and normal $(<10 \mathrm{mg} / \mathrm{dL})$ Phe level ( $\mathrm{P}=0.2799 ; 0.7959 ; 0.4812$, respectively).

Conclusions: The present study demonstrates that the cytochrome P450 activity in PKU patients may be reduced. However, further research is required, particularly in regards to the effect that patient diet compliance has on the microsomal liver function.
\end{abstract}

Keywords: Phenylketonuria, Microsomal Liver Function, Cytochrome P450, 13C Methacetin Breath Test

\section{Background}

Phenylketonuria, an inborn error of metabolism (PKU; OMIM 261600), is mainly considered in the context of neurological complications resulting from accumulation of phenylalanine and its metabolites. However, the essence of the disease is impairment of phenylalanine hydroxylase (PAH) activity in the liver, first observed by Jervis in 1953, which results in blocking of the conversion of phenylalanine to tyrosine (1-4). The treatment-compliance of PKU patients results in a normal life expectancy with health problems similar to that of the normal population and frequency of drug use. These factors tend to stress the liver's ability to metabolize xenobiotics. Although the activity of PAH, a cytosolic enzyme, was already assessed (5), the microsomal function of the liver, necessary for the metabolism of xenobiotics, has never been studied. The liver system engaged in the metabolism of drugs is the cytochrome P450 family (6).

The $13 \mathrm{C}$-methacetin breath test (13C-MBT) is a non- invasive, easy to perform and safe method used for the evaluation of microsomal liver function (7). Methacetin undergoes O-dealkylation by cytochrome P450 1A2 (CYP1A2) to acetaminophen and $13 \mathrm{CO} 2$ (8). $13 \mathrm{CO} 2$ output in exhaled air reflects the activity of cytochrome P450 enzymes and thereby microsomal function of the liver (9). The available data of previous studies show that 13C-MBT was used for the assessment of liver status in such conditions as hepatitis B and C (10), non-alcoholic steatohepatitis (11), fibrosis $(12,13)$ and cirrhosis $(13,14)$.

The aim of this study was to assess the microsomal liver function in PKU patients by 13C-MBT.

\section{Methods}

\subsection{Study Design}

The study group comprised of 20 subjects ( 13 females and 7 males) aged 15 - 34 years with classical PKU from the department of pediatric gastroenterology and metabolic 
diseases, medical university, Poznan and the Voivodeship hospital, Wroclaw, Poland.

Inclusion criteria were defined as: the diagnosis of classical PKU based on the result of national newborn screening and confirmed by molecular tests $(15,16)$, aged 15 years or older, and willingness to participate in the study. Exclusion criteria were: non-classical forms of PKU (mild PKU, maternal PKU, mild hyperphenylalaninemia, BH4 deficiency) and pregnancy. For analysis, the PKU patients were additionally divided into the group with recommended Phe levels $(<10 \mathrm{mg} / \mathrm{dL}$ ) and the group with high Phe levels (>10 mg/dL) - the cut-off levels were consistent with European guidelines for the diagnosis and management of PKU patients (17). The control group consisted of 20 healthy subjects matched for age and sex. The subjects did not take any drugs known to affect the CYP1A2 activity. Body mass and body height were measured and body mass index (BMI) was calculated in all study patients. Additionally, in the PKU group the diet compliance status was checked by the last Phe level before study entry using fluorometric method. As the study focused on microsomal function of the liver and CYP1A2 activity specifically, we did not assess the overall liver function characterized by liver enzymes activity as alanine aminotransferase, aspartate aminotransferase or gamma-glutamyl transferase. The study of liver function based on laboratory test results in PKU patients has already been performed (18). Moreover, none of the patients had the history of abnormal results of liver enzymes' activities in the past. The baseline characteristics of the study and control group is given in Table 1.

The 13C-MBT test was conducted at rest after an overnight fast. Before entrering the study, the subjects were instructed not to eat $13 \mathrm{C}$-naturally rich products such as pineapple, corn, cane sugar or kiwi for 2 days preceding the test (19). After basal breath sample collection (designated as "0"), each subject received $75 \mathrm{mg}$ of $13 \mathrm{C}$ Methacetin dissolved in $200 \mathrm{~mL}$ of unsweetened fruit tea. The samples of expiratory air were obtained every 10 minutes in the first hour and every 20 minutes in the second hour of the test ( 0 - basal, 10, 20, 30, 40, 50, 60, 80, 100, 120 minutes after substrate intake). The exhaled air samples were collected in plastic bags, closed immediately after exhalation and stored for analysis. The $13 \mathrm{CO} 2$ concentrations in the air samples were measured using isotope-selective nondispersive infrared spectrometry (IRIS, Wagner Analysen Technik GmbH, Bremen, Germany). From the obtained curve, the following parameters were derived: 1 , the maximum momentary $13 \mathrm{C}$ recovery (Dmax); 2 , the time of maximum Dmax occurrence (Tmax); 3, the cumulative percentage dose recovery at 120 minutes of the test (CPDR).

Informed written consent was obtained from every participant of the study. The study protocol was ap- proved by the local bioethics committee of the institutional review board at Poznan University of Medical Sciences, Poland (approval number 697/12).

\subsection{Statistical Analysis}

Considering the data from previous studies (20), it was assumed that the standard deviation would account for $22 \%$ of the mean value and the mean difference between the groups would be $20 \%$ of the cumulative percentage dose recovery at 120 minute (CPDR). To detect this difference with a power of $80 \%$ and a significance level of $5 \%$ while taking into account a potential drop-out rate of $10 \%$, it was calculated that twenty patients would be needed to be studied in each group.

Results are presented as medians with interquartile ranges and means \pm standard deviations (SD). The significance level was set at $\mathrm{P}<0.05$. The comparisons between the groups (PKU vs control and PKU with Phe level $<10$ $\mathrm{mg} / \mathrm{dL}$ vs PKU with Phe level $>10 \mathrm{mg} / \mathrm{dL}$ ) were performed with the use of Mann-Whitney U test. Statistical analysis was carried out with STATISTICA12 software packages (StatSoft Inc., Tulsa, USA).

\section{Results}

The characteristics of the selected breath test parameters in study and control group are presented in Table 2. The values of CPDR (median < interquartile range $>$ ) were significantly lower in the PKU group than in the control group $(25.1 \%<21.8-28.83>$ vs $32.8 \%<27.4-34.1>$; $\mathrm{P}=$ 0.0067). Similar results were obtained in regard to Dmax $(26.6 \%<22.4-28.7>$ vs $32.1 \%<27.18-34.08>$; $\mathrm{P}=0.0227)$. The values of Tmax (time to reach Dmax) did not differ between the PKU and control group (20 minutes $<17-20>$ vs. 20 minutes $<20-20>$; $\mathrm{P}=0.8410$ ). The distribution of selected breath test parameters in the PKU group with normal ( $<10 \mathrm{mg} / \mathrm{dL})$ and abnormal $(>10 \mathrm{mg} / \mathrm{dL})$ Phe level are shown in Figure 1. The values of CPDR, Dmax and Tmax were not different between the selected subgroups.

\section{Discussion}

The present study is the first one which demonstrates that cytochrome P450 activity in PKU patients is reduced in comparison to the control group. It is an unexpected phenomenon as the PKU diet which is rich in vegetables such as broccoli, Brussels sprouts $(21,22)$, is well known inducer of CYP1A2 activity, should stimulate microsomal liver function in PKU patients adhering to dietary treatment. The values of Dmax, Tmax and CPDR were not different between the patients with increased Phe concentration and 
Table 1. Baseline Characteristics of the PKU and Control Group

\begin{tabular}{|c|c|c|c|c|c|}
\hline & \multicolumn{2}{|c|}{ Study Group n = 20 (13 F, 7 M) } & \multicolumn{2}{|c|}{ Control Group $n=20(13 \mathrm{~F}, 7 \mathrm{M})$} & \multirow[t]{2}{*}{ P Value } \\
\hline & Mean $\pm S D$ & Median (1st Quartile-3rd Quartile) & Mean \pm SD & Median (1st Quartile-3rd Quartile) & \\
\hline Age (years) & $23.9 \pm 5.32$ & $23.0(20.00-27.50)$ & $27.7 \pm 5.63$ & $22.5(18.75-27.00)$ & 0.7583 \\
\hline Body weight (kg) & $59.8 \pm 7.0$ & $60.0(54.3-64.4)$ & $62.4 \pm 9.4$ & $61.1(57.0-68.5)$ & 0.3834 \\
\hline Body height (m) & $1.68 \pm 0.07$ & $1.68(1.64-1.73)$ & $1.70 \pm 0.08$ & $1.69(1.64-1.77)$ & 0.5648 \\
\hline BMI $\left(\mathrm{kg} / \mathrm{m}^{2}\right)$ & $21.14 \pm 1.86$ & $20.92(20.04-22.19)$ & $21.51 \pm 2.22$ & $21.39(19.70-23.57)$ & 0.6980 \\
\hline Phe (mg/dL) & $9.19 \pm 5.99$ & $8.90(3.84-13.51)$ & - & - & \\
\hline
\end{tabular}

Table 2. Characteristics of Selected Breath Test Parameters in Study and Control Group

\begin{tabular}{|c|c|c|c|c|c|}
\hline & \multicolumn{2}{|r|}{ Study Group } & \multicolumn{2}{|r|}{ Control Group } & \multirow[t]{2}{*}{ P Value } \\
\hline & Mean \pm SD & Median (1st Quartile- 3rd Quartile) & Mean \pm SD & Median (1st Quartile-3rd Quartile) & \\
\hline $\operatorname{Tmax}(\min )$ & $20 \pm 7.8$ & $20(17.5-20.0)$ & $19 \pm 5.4$ & $20(20.0-20.0)$ & 0.841013 \\
\hline $\operatorname{Dmax}(\%)$ & $26.3 \pm 4.8$ & $26.6(22.4-28.7)$ & $31.5 \pm 7.1$ & $32.1(27.2-34.1)$ & 0.022719 \\
\hline CPDR (\%13C) & $25.9 \pm 6.2$ & $25.1(21.8-28.8)$ & $30.3 \pm 7.0$ & $32.8(27.4-34.1)$ & 0.006715 \\
\hline
\end{tabular}

Abbreviations: CPDR, the cumulative percentage dose recovery at 120 minutes; Dmax, the maximum momentary $13 \mathrm{C}$ recovery; Tmax, time to reach Dmax.

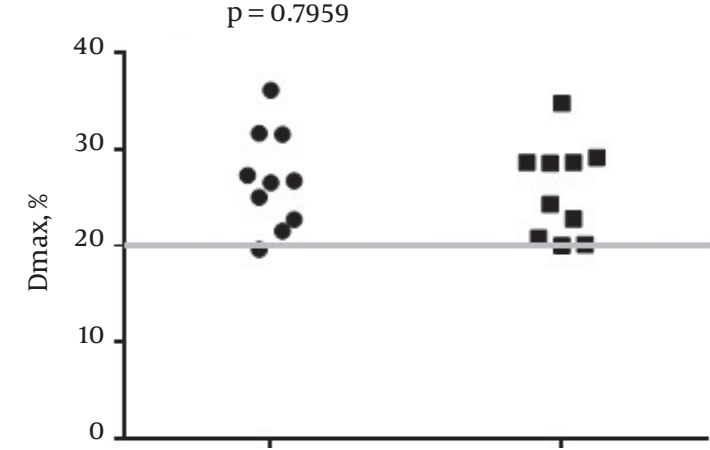

Phe $>10 \mathrm{mg} / \mathrm{dL} \quad$ Phe $>10 \mathrm{mg} / \mathrm{dL}$

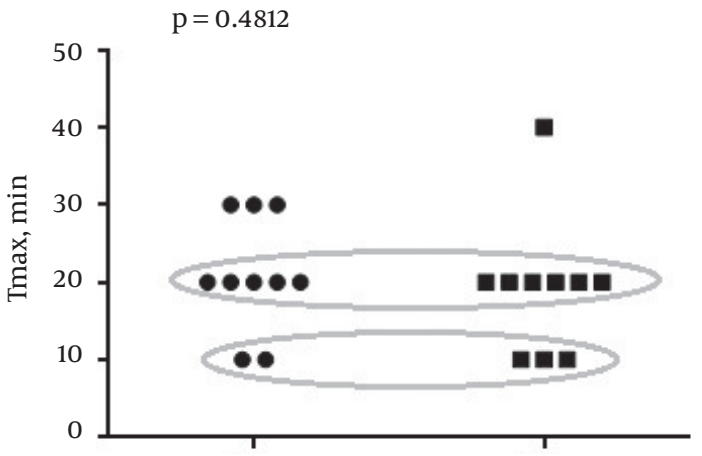

Phe $>10 \mathrm{mg} / \mathrm{dL} \quad$ Phe $>10 \mathrm{mg} / \mathrm{dL}$

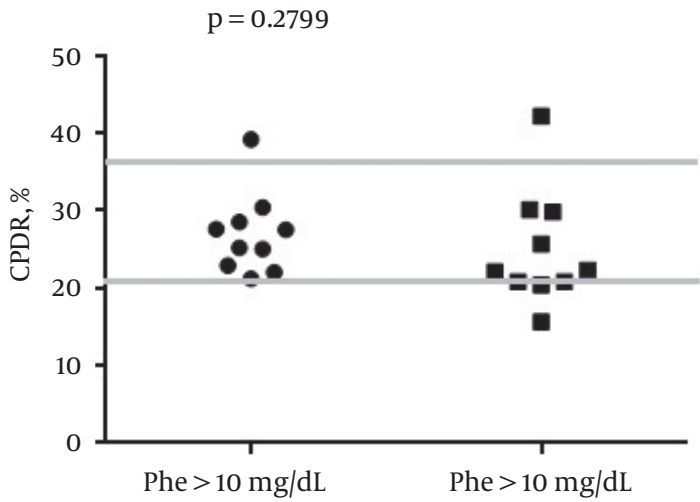

Figure 1. Frequency Plots of Dmax, Tmax and CPDR in the PKU Groups with Recommended $(<10 \mathrm{mg} / \mathrm{dL})$ and Exceeded $(>10 \mathrm{mg} / \mathrm{dL}) \mathrm{Phe}$ Level 
subjects with normal phenylalanine concentration. The aforementioned observation may suggest that deterioration of microsomal liver function in PKU is not strictly related to Phe levels. However, the sample size in the present study was small and further research studies are required.

The innovation of the present study lies in the fact that we aimed to assess the cytochrome P450 function in the PKU subjects. Until now, the status of microsomal liver function in these patients has not been the object of scientific interest. Turki et al used a minimally-invasive 1 (13) C-phenylalanine breath test to examine phenylalanine metabolism in children with PKU (5). Although 13C-PBT estimates metabolic liver capacity, it is focused on cytosolic function directly, which makes it useless in the evaluation of cytochrome P450 activity (7). The strength of this study was the use of the validated method of 13C-MBT as it is most accurate to assess the cytochrome P450 function. 13C-MBT is also non-invasive and safe for patients. No side effects of the test have been reported in the literature (20). Along with the 13C-aminopyrine breath test, it is the most extensively studied of the liver breath tests. Although the 13C-MBT test is strongly dependent on hepatic blood flow $(7,9)$, we decided to use $13 \mathrm{C}$ methacetin instead of another substrate due to its high safety index (20) Furthermore, there are no available data describing alterations of hepatic blood flow in PKU patients. As there are many conditions affecting the cytochrome P450 function (7), the present study was designed to eliminate potential bias - the control group was matched for age and sex, all the participants were instructed not to smoke cigarettes and avoid 13C-naturally rich products, and the test was performed after an overnight fast.

The present study is the first one focused on the assessment of cytochrome P450 activity of the liver in PKU patients. So far there were only a few research projects trying to evaluate liver function in subjects with this disease. However, none of the studies provided information regarding metabolic capacity. Boger et al measured 11 laboratory parameters in PKU related to liver function. On the basis of the obtained results, the absence of any abnormalities of liver function was affirmed. Although the parameters used in the aforementioned study are basic and commonly used, they do not indicate any metabolic dysfunction of the liver $(9,18)$. Furthermore, Ramati et al observed that low blood concentrations of vitamin B6 (the source for ALT co-factor, Pyridoxal-5-Phosphate) results in lower ALT activity amongst patients of internal medicine departments (23). As the majority of PKU patients had a vitamin B6 intake below recommended daily intake (24), it should not be excluded that the results of Boger at al might be affected due to insufficient consumption of this vitamin.

Numerous studies comprising PKU patients are fo- cused on the new therapeutic targets. However, gathering knowledge about metabolic capacity of the liver in regards to the metabolism of xenobiotics also seems to be an important scientific field of interest. The present study demonstrates that the cytochrome P450 activity in PKU patients is disturbed. Observed CYP1A2 inhibition may result in a slower metabolism of drugs and lower doses of substances metabolized by CYP1A2 should be potentially considered in PKU patients. However, further research is required, particularly in regards to the effect that patient diet compliance has on the microsomal liver function.

\subsection{Conclusions}

The present study demonstrates that the cytochrome P450 activity in PKU patients may be reduced. However, further research is required, particularly in regards to the effect that patient diet compliance has on the microsomal liver function

\section{References}

1. Vockley J, Andersson HC, Antshel KM, Braverman NE, Burton BK Frazier DM, et al. Phenylalanine hydroxylase deficiency: diagnosis and management guideline. Genet Med. 2014;16(2):188-200. doi: 10.1038/gim.2013.157. [PubMed: 24385074].

2. Blau N, van Spronsen FJ, Levy HL. Phenylketonuria. Lancet. 2010;376(9750):1417-27. doi: 10.1016/S0140-6736(10)60961-0. [PubMed: 20971365].

3. Scriver CR. The PAH gene, phenylketonuria, and a paradigm shift Hum Mutat. 2007;28(9):831-45. doi: 10.1002/humu.20526. [PubMed: 17443661].

4. Jervis GA. Phenylpyruvic oligophrenia deficiency of phenylalanineoxidizing system. Proc Soc Exp Biol Med Soc Exp Biol Med NYN 1953;82(3):514-5.

5. Turki A, Murthy G, Ueda K, Cheng B, Giezen A, Stockler-Ipsiroglu S, et al. Minimally invasive (13)C-breath test to examine phenylalanine metabolism in children with phenylketonuria. Mol Genet Metab. 2015;115(2-3):78-83. doi: 10.1016/j.ymgme.2015.04.005. [PubMed: 25943030].

6. Lu AY. Liver microsomal drug-metabolizing enzyme system: functional components and their properties. Fed Proc. 1976;35(13):2460-3. [PubMed: 824157].

7. Afolabi P, Wright M, Wootton SA, Jackson AA. Clinical utility of 13Cliver-function breath tests for assessment of hepatic function. Dig Dis Sci. 2013;58(1):33-41. doi: 10.1007/s10620-012-2340-z. [PubMed: 22899241].

8. Ilan Y. Review article: the assessment of liver function using breath tests. Aliment Pharmacol Ther. 2007;26(10):1293-302. doi: 10.1111/j.1365 2036.2007.03519.x. [PubMed: 17868431].

9. Pijls KE, de Vries H, Nikkessen S, Bast A, Wodzig WK, Koek GH. Critical appraisal of $13 \mathrm{C}$ breath tests for microsomal liver function: aminopyrine revisited. Liver Int. 2014;34(4):487-94. doi: 10.1111/liv.12451. [PubMed: 24428683].

10. Goetze O, Selzner N, Fruehauf H, Fried M, Gerlach T, Mullhaupt B. 13C methacetin breath test as a quantitative liver function test in patients with chronic hepatitis $\mathrm{C}$ infection: continuous automatic molecular correlation spectroscopy compared to isotopic ratio mass spectrometry. Aliment Pharmacol Ther. 2007;26(2):305-11. doi: 10.1111/j.13652036.2007.03360.x. [PubMed: 17593076]. 
11. Portincasa P, Grattagliano I, Lauterburg BH, Palmieri VO, Palasciano G Stellaard F. Liver breath tests non-invasively predict higher stages of non-alcoholic steatohepatitis. Clin Sci (Lond). 2006;111(2):135-43. doi: 10.1042/CS20050346. [PubMed:16603025].

12. Lalazar G, Pappo O, Hershcovici T, Hadjaj T, Shubi M, Ohana H, et al A continuous $13 \mathrm{C}$ methacetin breath test for noninvasive assessment of intrahepatic inflammation and fibrosis in patients with chronic HCV infection and normal ALT. J Viral Hepat. 2008;15(10):716-28. doi 10.1111/j.1365-2893.2008.01007.x. [PubMed: 18638013].

13. Dinesen L, Caspary WF, Chapman RW, Dietrich CF, Sarrazin C Braden B. 13C-methacetin-breath test compared to also noninvasive biochemical blood tests in predicting hepatic fibrosis and cirrhosis in chronic hepatitis C. Dig Liver Dis. 2008;40(9):743-8. doi: 10.1016/j.dld.2008.01.013. [PubMed: 18339592].

14. Vranova J, Hendrichova M, Kolarova H, Kratka K, Rosina J, Horak J (1)(3)C-methacetin breath test in the evaluation of disease severity in patients with liver cirrhosis. Biomed Pap Med Fac Univ Palacky Olomouc Czech Repub. 2013;157(4):392-400. doi: 10.5507/bp.2012.114. [PubMed: 23549507].

15. Gizewska M, MacDonald A, Belanger-Quintana A, Burlina A, Cleary M Coskun T, et al. Diagnostic and management practices for phenylketonuria in 19 countries of the South and Eastern European Region survey results. Eur JPediatr. 2016;175(2):261-72. doi:10.1007/s00431-015 2622-5. [PubMed: 26350228].

16. Bik-Multanowski M, Kaluzny L, Mozrzymas R, Oltarzewski M, Starostecka E, Lange A, et al. Molecular genetics of PKU in Poland and potential impact of mutations on $\mathrm{BH} 4$ responsiveness. Acta Biochim Pol. 2013;60(4):613-6. [PubMed: 24350308]

17. van Spronsen FJ, van Wegberg AMJ, Ahring K, Bélanger-Quintana A
Blau N, Bosch AM, et al. Issues with European guidelines for phenylketonuria - Authors' reply. Lancet Diabet Endocrinol. 2017;5(9):683-4. doi: 10.1016/s2213-8587(17)30202-4.

18. Boger WP, McClelland J, Gavin JJP. Measurement of multiple parameters of liver function. Am J Clin Nutr. 1967(5):446-51.

19. Jonderko K, Kasicka-Jonderko A, Kaminska M, Blonska-Fajfrowska B. A systematic study of a neutral meal suitable for subjects undergoing 13CO2 breath tests. Med Sci Monit. 2008;14(10):CR543-6. [PubMed: 18830195].

20. Ciccocioppo R, Candelli M, Di Francesco D, Ciocca F, Taglieri G, Armuzzi A, et al. Study of liver function in healthy elderly subjects using the 13C-methacetin breath test. Aliment Pharmacol Ther. 2003;17(2):2717. [PubMed: 12534413].

21. Hakooz N, Hamdan I. Effects of dietary broccoli on human in vivo caffeine metabolism: a pilot study on a group of Jordanian volunteers. Curr Drug Metab. 2007;8(1):9-15. [PubMed:17266520].

22. Lake BG, Tredger JM, Renwick AB, Barton PT, Price RJ. 3,3'Diindolylmethane induces CYP1A2 in cultured precisioncut human liver slices. Xenobiotica. 1998;28(8):803-11. doi: 10.1080/004982598239227. [PubMed: 9741959].

23. Ramati E, Israel A, Tal K, Petz-Sinuani N, Sela BA, Idan G, et al. [Low ALT activity amongst patients hospitalized in internal medicine wards is a widespread phenomenon associated with low vitamin B6 levels in their blood]. Harefuah. 2015;154(2):89-93. [PubMed: 25856859] 137.

24. Hvas AM, Nexo E, Nielsen JB. Vitamin B12 and vitamin B6 supplementation is needed among adults with phenylketonuria (PKU). J Inherit Metab Dis. 2006;29(1):47-53. doi:10.1007/s10545-006-0108-3. [PubMed: 16601867]. 